\title{
Adesão, permanência e dificuldades encontradas por mulheres, da cidade de Limoeiro do Norte no futsal: um estudo de caso
}

https://doi.org/10.11606/issn.1981-4690.v35inespp83-91

\author{
Valderlene Costa do Nascimento* \\ Marcelo Alencar Leite*
}

*Instituto Federal de

Educação Ciência e

Tecnologia do Ceará,

Ceará, CE, Brasil.

\begin{abstract}
Resumo
0 presente trabalho teve por objetivo investigar os motivos que levaram mulheres da cidade de Limoeiro do Norte a buscarem a prática do futsal e sua permanência nessa prática. A amostra foi composta por nove mulheres de um time de futsal da cidade de Limoeiro do Norte que possuem idade entre 18 e 46 anos. Para a coleta de dados utilizamos uma entrevista semiestruturada e o Participation Motivation Questionnair (PMO) criado por Gil, Gross e Huddleston (1983), traduzido e adaptado para o português por Guedes e Silvério Netto (2013) que traz como itens fatores intrínsecos e extrínsecos a serem escolhidos em uma escala de 1 a 5 como "Nada importante" e "Muito importante", respectivamente. Os dados foram analisados por categorização como sugere o autor do PMO e a entrevista foi também categorizada. Os resultados mostram que as atletas tinham como motivos predominante de adesão ao futsal as categorias Competição, Competência técnica, Aptidão física que reúnem itens como vencer desafios, melhorar habilidades técnicas, manter a forma física e algumas das atletas sofreram influência dos familiares para essa adesão. Como motivos para permanência as atletas elencaram a busca por uma melhor qualidade de vida e amor ao esporte em questão, mesmo diante de dificuldades que também são apontadas, como falta de tempo devido a dupla jornada de trabalho que a maioria das entrevistadas possui, além do reconhecimento, valorização, comprometimento de parte das atletas e ainda da gestão atual que pouco apoia o futsal feminino na cidade. Concluindo é possivel afirmar que as atletas são motivadas principalmente por fatores externos, mas persistem por fatores internos, que levam a satisfação pessoal e que as dificuldades precisam do apoio de todos para serem superadas, pois estão além das quadras a maioria das dificuldades apontadas.
\end{abstract}

Palavras-chave: Futsal feminino; Adesão; Permanência; Dificuldades; Limoeiro do Norte.

\section{Introdução}

O futsal é um esporte que surge como uma forma adaptada para a prática do futebol de campo, mas ainda há controvérsia sobre sua origem, pois alguns autores citam surgimento na década de 30 na Associação Cristã de Moços em Montevidéu, no Uruguai ${ }^{1,2}$ baseado no futebol, handebol, basquete e polo aquático, enquanto a Confederaçáo Brasileira de Futebol de Salão (CBFS) cita origem na década de 40 por frequentadores da Associaçáo Cristã de Moços em São Paulo, no Brasil ficando conhecido na época como esporte da bola pesada.

No Brasil, o futsal passa a ser oficializado em todo o país no ano de 1958 pela Confederação Brasileira de Desporto (CBD) com a criação do Conselho Técnico de Futebol de Saláo. A partir de entâo, tentaram padronizar todas as regras para que houvesse a possibilidade de realizar competições nacionais ${ }^{1}$. No ano de 1983, o Conselho Nacional de Desporto (CND) oficializa a prática de futsal para as mulheres, que até entáo, estavam permitidas de irem ao ginásio apenas para acompanhar seus maridos, "fazendo o papel de coadjuvante, a mãe que lava os uniformes, a irmá que limpa as chuteiras, a namorada que prepara e serve as bebidas, etc" como afirma Moura ${ }^{3}$ (p.140). Partimos desse momento em que as mulheres se tornam parte de um universo, até então, exclusivo para os homens e no qual a procura pela prática desse esporte vem aumentando por parte do público feminino.

Neste sentido cabe questionarmos quais são os motivos responsáveis pela adesão de mulheres na prática deste esporte? Como complemento desta problemática, também questionamos quais os fatores de permanência destas mulheres no esporte em questão? 
Diante dessas questóes traçamos como objetivo investigar os motivos que levaram mulheres da cidade de Limoeiro do Norte a buscarem a prática do futsal e sua permanência nessa prática.

\section{Histórico do futsal}

Alguns autores citam Montevidéu, no Uruguai, como sendo o berço desse esporte, através do professor Juan Carlos Ceriani, na década de $30^{1,2}$, denominado como Indoor-Foot-Ball, enquanto outros citam a Associação Cristã de Moços em São Paulo na década de 40, ficando conhecido no Brasil como o esporte da bola pesada ${ }^{4,5}$.

O futsal, como hoje é conhecido, não tinha regras padronizadas até que o presidente da CBD, Sr. Sylvio Pacheco, em 1957 resolveu instituir um Conselho técnico para elaborar regras que fossem aplicadas em todo o território nacional, com adaptaçóes do futebol, basquetebol, handebol e polo aquático5. A Confederação Brasileira de Futebol de Salão (CBFS) foi fundada em 15 de junho de 1979, tendo como presidente Aécio de Borba Vasconcelos e sede oficial na cidade de Fortaleza, no Ceará, ${ }^{4}$.

Somente na década de 1980 o Futebol de Salão passa a ser chamado de Futsal. A partir de um impasse entre dirigentes da FIFA (Federação Internacional de Futebol) e FIFUSA (Federação Internacional de Futebol de Saláo), instituiçóes que lutavam pelo controle da modalidade e devido seu avanço nacional e internacionalmente. Sobre o comando da FIFA o futsal se expande pelo mundo, no Brasil se fixa em todos os níveis, fazendo parte até mesmo das competiçóes escolares.

\section{Mulheres no esporte, especificamente no futsal}

Quando tratamos das mulheres inseridas em qualquer esporte, temos que trazer à tona muitos acontecimentos históricos que permitiram serem inseridas e aceitas em esportes como o judô e as lutas de um modo geral, o futebol, pólo aquático, entre outros.

No entanto devemos citar que houve épocas em que apoiadas pelos médicos higienistas, sobre os benefícios do exercício físico, modalidades como hipismo e tênis "eram anunciadoras de laços igualitários entre os sexos", o tênis por ter a elegância das elites europeias sem tirar da mulher sua feminilidade e o hipismo por ser uma paixão da oligarquia ${ }^{6}$.

No Brasil a história da educação física contribui para a caracterização dos comportamentos femininos e masculinos, mantendo papéis distintos e separados por sexo, como afirma Castellani Filho ${ }^{7}$ (p. 45): A educação fisica da mulher deve ser, portanto, integral, higiênica e plástica, [...], cingir-se exclusivamente aos jogos e esportes menos violentos e de todo compativeis com a delicadeza do organismo das mães.

Na tentativa de ampliar a visibilidade para as mulheres praticantes de esportes foi organizado, em centros urbanos do país, competiçóes exclusivamente para mulheres, como os Jogos da Primavera e os Jogos abertos Femininos que aconteceram em 1949 e 1954, respectivamente ${ }^{6}$.

Com essas atitudes e com a insatisfação de alguns setores da sociedade brasileira foi elaborada pela legislação da Educação Física e do esporte, documentos no qual diz "não se permitirá a prática de desportos incompatíveis com as condiçōes de sua natureza" (Lei n. 3.199 - Art. 54). Sustentado pela deliberaçáo do CND de número 7/65 que cita esportes como "lutas de qualquer natureza, futebol, futebol de salão, futebol de praia, polo aquático, polo, rúgbi, halterofilismo e baseball" (p. 49) no qual não se deve ter mulher na sua prática sob o discurso da fragilidade feminina, pela valorização da imagem de uma mulher frágil e delicada.

O futsal, assim como o futebol, é tido como um esporte masculinizado por ser um esporte com características rudes, violentas e de força, velocidade e rigidez, estando a prática esportiva feminina ligada ao critério da beleza, da sutileza, portanto, "para uma menina, assumir determinados comportamentos historicamente vistos como masculinos, como ser mais agressiva, ou jogar futebol. Pressupöe ir contra uma tradição's (p. 77).

Mesmo perante todas essas barreiras não significa dizer que todas as mulheres deixaram de praticar as modalidades contraindicadas para seu sexo. Elas continuavam a sua prática informalmente até que fosse liberado sua participação em competições oficiais.

No Brasil, quando tratando do futsal feminino essa autorização aconteceu em 1983 pela FIFUSA, a partir dessa autorizaçáo os campeonatos começaram a surgir em vários estados, como aponta Pereira e Antunes9 em 1992 aconteceu o primeiro campeonato oficial pela CBFS: I Taça Brasil de Clubes que teve o número de dez (10) equipes participantes indicadas por suas Federaçóes.

A partir de 1992 os campeonatos estaduais são organizados em quase todos os estados, levando os campeóes de cada estado a garantir vaga na disputa da Taça Brasil do ano seguinte. 
Em 2001 acontece a convocação da primeira seleçáo brasileira para um desafio internacional contra o Paraguai, tendo como técnica Maria Cristina Oliveira. Em 2002 aconteceu o primeiro Campeonato Brasileiro de Seleçóes Femininas na cidade de São Paulo ${ }^{10}$. Em 2005 a seleção brasileira é convocada mais uma vez para amistosos na Espanha e disputou o I Campeonato Sul-Americano na cidade de Barueri. A CBFS criou, ainda em 2005, a I Liga de Futsal Feminino e as Taças Brasil do Sub-15, 17, 20 e o Campeonato Brasileiro de seleçóes?.

No ano de 2019, a Taça Brasil chegou a sua 27a edição consagrando campeã a equipe Leoas da serra, que tem em seu elenco a atual melhor do mundo, Amanda Lyssa, mais conhecida como Amandinha. O clube que também é o atual campeão mundial de interclubes. O torneio foi disputado em Lages-SC e contou com a participação de oito equipes.

A necessidade de expandir o futsal feminino no Brasil e no mundo tem como principal motivo aumentar o número de participantes para incluir a modalidade nas olimpíadas. Além disso o futsal feminino deve ser visto e apoiado de maneira diferente de como é atualmente, pois mesmo com o crescimento significante, tanto em quantidade de times quanto em qualidade dos times que estáo em competição sofre preconceitos ao entrar em quadra ou até mesmo quando acompanha um jogo de homens e escuta "joga como uma mulherzinha".

\section{Motivaçáo}

A motivação é geralmente estudada na área psicológica, mas com os avanços nos estudos, sua aplicação de conhecimento vem sendo utilizada por profissionais de atividades físicas e desportivas, auxiliando no planejamento e organizaçáo das aulas e treinamentos. Na prática dos esportes a motivação pode estimular o indivíduo de diversas formas, visto que ela pode variar de um indivíduo para outro. Muitos atletas possuem diferentes maneiras de tratar tal prática, para uns os motivos podem ser relativamente fortes e fraco para outros.

Ao falar em motivação podemos levar em consideração a definição citada por ReEvE ${ }^{11}$, em que relaciona o termo motivaçáo à palavra motivo, definindo como um processo interno que fortalece, necessidades e desejos que conduz o indivíduo a uma certa direção e a motivaçáo compreende o comportamento de determinado indivíduo para alcançar um objetivo. Essa definição tem reforço em MACHADO ${ }^{12}$, quando fala que, a motivação é um termo que abrange qualquer comportamento dirigido para um objetivo ou estado interior, emocional, que desperta o interesse do indivíduo para algo, estando este desposto a descartar os esforços para alcança-los.

Dessa maneira, Sage (apud Weinberg; Gould, $2008)^{13}$ acreditam que a motivação pode ser indicada simplesmente como a direção e a intensidade dos esforços humanos. A direção do esforço refere-se à busca, à aproximação ou à atração de um indivíduo por certas situaçóes, enquanto que a intensidade se refere à força - maior ou menor - que uma pessoa ou atleta investe no esforço em uma determinada situaçáo.

Para ReEve ${ }^{11}$ a motivação pode ter dois pontos de vista: motivação intrínseca e extrínseca. A motivação intrínseca é a vontade que a pessoa possui em pôr em prática seus próprios interesses, apenas pelo prazer de fazer e gostar de vencer mais aquele desafio lançado. A motivação extrínseca manifesta-se através dos incentivos, estímulos externos. Essas formas de motivação podem e devem ser observadas e levadas em consideração quando estamos diante de uma equipe em treinamento, os atletas são motivados geralmente por uma combinação de motivação intrínseca e extrínseca, pois cada indivíduo apresenta motivações intrínsecas diferentes e reagem a determinadas formas de motivação extrínseca.

No estudo de Voser e colaboradores ${ }^{14}$ ao investigar a motivação para a prática de futsal, realizado com atletas federados da categoria adulto masculino e feminino de um clube de Porto Alegre, e utilizando o questionário de Motivação para a prática no esporte apontou que os atletas do sexo masculino possuem maior motivaçáo em todas as dimensóes quando comparadas as do sexo feminino.

O estudo de Gaviáo, Falcão e Ilha ${ }^{15}$ ao buscar identificar os aspectos motivacionais que promovem a adesão, a permanência e as barreiras percebidas de mulheres à prática do futebol sete amador, com amostra composta por dezessete mulheres de um grupo de jovens de um município da regiáo oeste do Rio Grande do Sul. Aponta que as atletas tinham como aspecto motivacional predominante, para a prática do futebol, a dimensão prazer, seguida do controle de stress. A principal influência para adesão ao futebol foi a Educação Física escolar e as barreiras para a prática do futebol feminino foram poucas evidenciadas, restringindo-se a espaço físico, situação financeira, jornada dupla de trabalho e preconceitos relativos ao machismo 
cultural. Concluindo que as atletas de futebol feminino se motivam principalmente pelo prazer individual de cada componente, onde o controle de stress e a sociabilidade tem grande influência na participação dessas meninas no esporte e que o apoio da família e amigos é muito importante para o grupo e esse torna-se incentivo diário na permanência no meio futebolístico.

\section{Resultados e discussão}

\section{Histórico do futsal feminino em Limoeiro do} Norte

Quando traçamos o objetivo de conhecer a história do futsal feminino em Limoeiro do Norte, nos propomos a buscar por documentos físicos ou on-line, livros, entrevistas nas mídias da cidade, na qual pudéssemos apontar cada momento, cada evoluçáo e conquista desse time. No entanto, ao procurar a entidade responsável pelo esporte da cidade não obtivemos êxito na busca por tais registros. Conseguimos alguns registros arquivados por uma exatleta. Esse é o registro do primeiro grupo de mulheres que representou a cidade em competições pelo estado, nos anos 90 e início dos anos 2000.

Ao visitar o Ginásio José Nilson Osterne, sede da Secretaria de Esportes do Município, encontramos placas de homenagem de uma época em que não tivemos acesso nas mídias, uma época de títulos e de renovação.

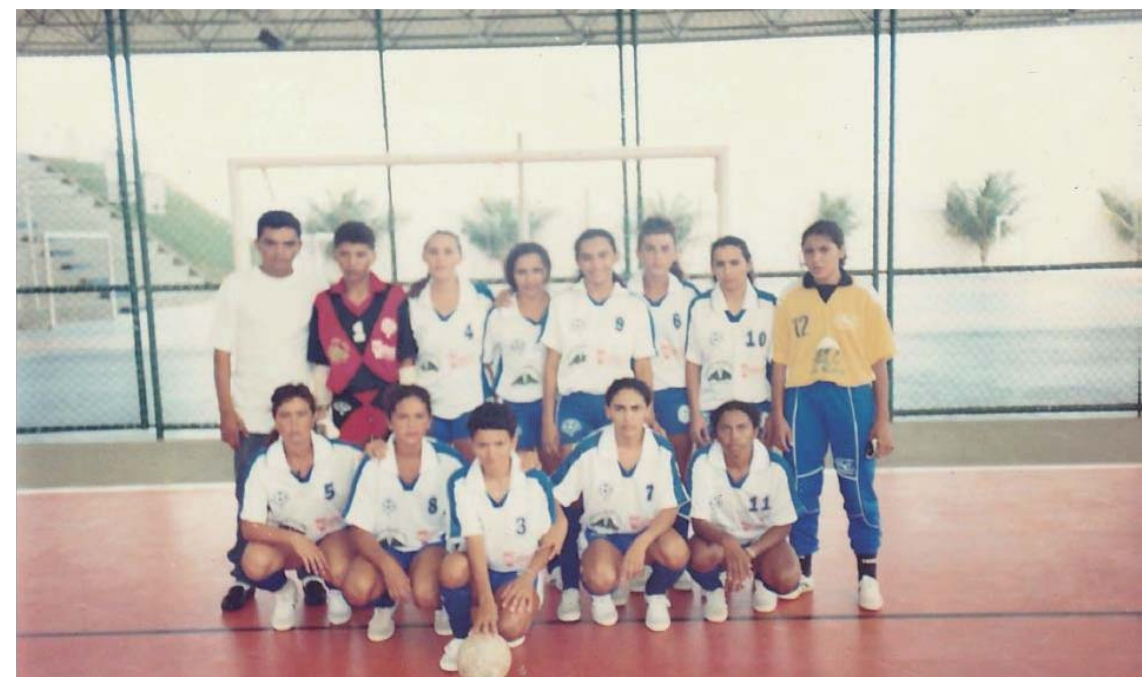

FIGURA 1- Seleção de Limoeiro do Norte, ano de 1998.

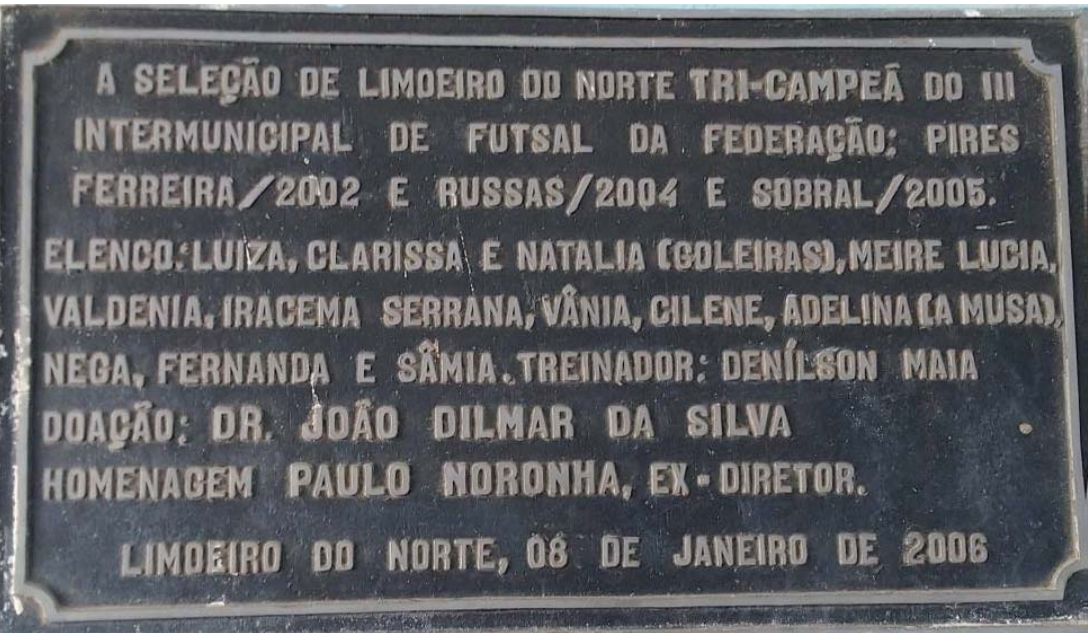

FIGURA 2 - Placa de homenagem a seleção de Limoeiro do Norte, ano de 2006. 


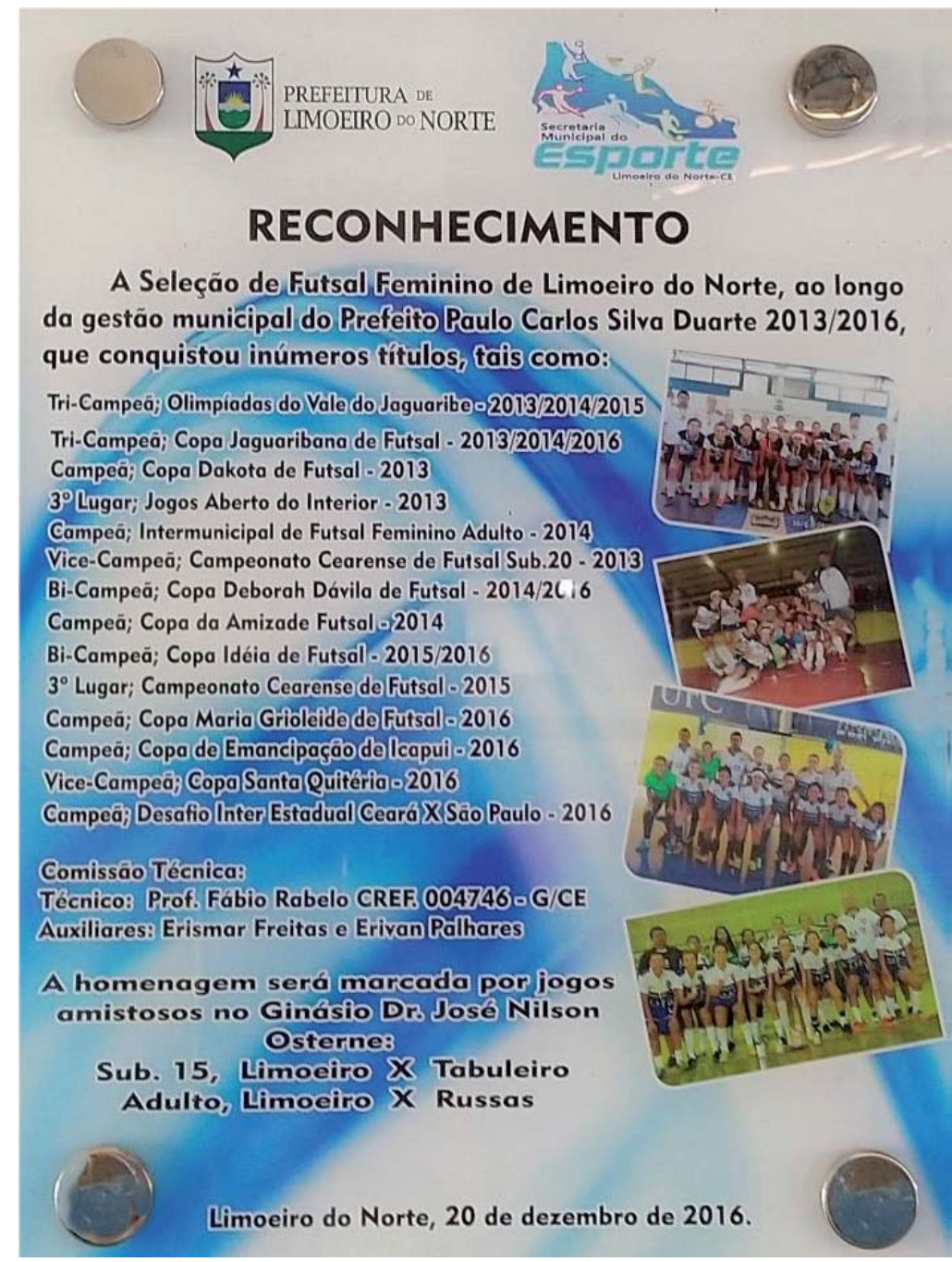

FIGURA 3 - Placa de reconhecimento, ano 2013/2016.

No ano de 2016 é fundado um novo clube de futsal feminino, Clube Limoeirense de Futsal Feminino (CLFF) idealizado pelas atletas que praticam futsal e disputam competiçóes anuais. O Clube oferecia atividades nas categorias de base e também para o grupo principal de maneira gratuita, esse grupo se tornou o novo representante do município nas competiçóes comandado pelo Professor Fábio Rabelo ${ }^{16}$.

No período entre 2017 e 2020 o time participou de algumas competiçóes no estado como Campeonato Intermunicipal, Copa Princesa do Vale, Campeonato Cearense, Copa Jaguaribana de Futsal, Jogos Abertos do Ceará. Em Julho de 2019, Limoeiro do Norte consagra-se campeã do II Regionalito de Futsal Feminino, sediada pela cidade de Quixadá essa competição contou com a participaçáo de 12 (doze) equipes e recentemente Campeã dos Jogos Abertos do Ceará vencendo a equipe de Crateús.
Com a mudança de gestão municipal, por muitas vezes acabam mudando o comando das secretarias, e por consequência também os comandos das equipes representantes do município. Atualmente os treinamentos estáo parados e ainda sem nenhuma nomeação concreta para assumir tal comando.

\section{Adesão}

Participaram da pesquisa 9 atletas com idade entre 18 e 46 anos. As questôes do questionário foram analisadas por tópicos como sugere o autor do PMQ: Reconhecimento social (7 itens), atividade em grupo (4 itens), aptidão física (4 itens), Emoção (3 itens), competição ( 2 itens), competência técnica (3 itens), afiliação (3 itens), diversão ( 4 itens) e divididos para obter uma média entre cada uma dessas categorias, na qual segue na TABELA 1. 
TABELA 1 - Média do grau de motivação das atletas na prática do futsal.

\begin{tabular}{lc}
\multicolumn{1}{c}{ Categorias } & Média \\
\hline Reconhecimento social & 3,46 \\
Atividade em grupo & 3,87 \\
Aptidáo física & 4,78 \\
Emoçáo & 4,33 \\
Competiçáo & 4,91 \\
Competência técnica & 4,83 \\
Afiliaçáo & 3,29 \\
Diversão & 3,62 \\
\hline
\end{tabular}

Os resultados foram analisados por categoria e conforme pode ser observado na TABELA 1 os itens que levam as atletas à prática de futsal, com uma média mais alta, foram os itens Competição, Competência técnica e Aptidão física, com 4.91, 4.83 e 4.73 respectivamente e com menor média a categoria Afiliação.

A categoria competiçáo envolve itens como "competir" e "vencer desafios" demonstrando que para as atletas analisadas o fato de vencer os desafios propostos é muito importante.

A categoria competência técnica inclui itens como "melhorar habilidades técnicas" e "aprender novas habilidades" mostrando que além de buscar pela competição as atletas buscam pelo aprendizado.

A categoria aptidão física engloba itens como "manter a forma física" e "estar em boas condições físicas", entretanto, isso pode ser reflexo da influência da sociedade que muitas vezes acaba sendo utilizada como pré-requisito para aceitação ou rejeição social ${ }^{17}$, podendo ainda estar relacionado com a saúde.

$\mathrm{Na}$ categoria com menor média, afiliação, estão os itens "satisfazer a família e os amigos", "estar com os amigos" e "fazer novas amizades", tal resultado pôde também ser visto no estudo de Correia e SiLvério NetTo $^{18}$, estudo que tinha como objetivo investigar quais os principais motivos para a prática do futsal de atletas de um time feminino e seus fatores associados sociodemográficos e clima social percebido.

Com base na entrevista semiestruturada podemos ver que além dos motivos nomeados pelo questionário $\mathrm{PMQ}$, sete das atletas iniciaram ao esporte por "vontade própria", "por amor ao futsal", "por gostar da modalidade", mas ainda indiretamente sofreram influência de pais ou familiares, como destaca algumas das atletas:

"[...] era só o que meus irmãos e meu pai faziam e daí eu fazia com eles" (A1).

"[...] sempre vi meus pais praticarem esportes" (A2) .
“[...] meu pai era treinador e isso ajudou um pouco" (A3).

A família é o ambiente social em que os atletas desenvolvem sua identidade, autoestima e motivação para o sucesso nos esportes. O bom desempenho de um atleta se deve, muitas vezes, ao encorajamento da família, atribuição de valores, além do apoio psicológico durante a carreira ${ }^{19}$. O incentivo da família é de extrema importância e ainda mais quando se trata de uma modalidade onde há preconceitos envolvidos, onde as atletas são vistas de maneira diferente pela sociedade.

\section{Permanência}

Ao tratar da permanência das mulheres a um esporte masculinizado, quando perguntadas sobre o que motiva continuar jogando até hoje, sete das nove entrevistadas continuam por amor ao esporte, mas ainda são citados:

"[...] a busca por uma qualidade de vida melhor" (A4).

"[...] me tira o estresse, me proporciona qualidade de vida." (A5).

É de extrema importância apontar essas questóes sobre qualidade de vida pois para cada faixa etária existe um tipo de esporte, idade e o estado de saúde atual é a medida de todas as coisas e isso acaba possibilitando um melhor aproveitamento não só dentro de quadra, mas na sua rotina diária, o esporte pode se tornar eficiente para a saúde quando praticado frequentemente.

Além de buscar entender o lado de por que continuar, buscamos também entender se elas tinham remuneração para tal atividade, afinal é um estímulo externo, uma maneira de incentivar as atletas a continuar e buscar sempre a evoluçáo. E diante da pergunta: Possui remuneração na 
atuação do futsal? A maioria das respostas foi "Não", mas ainda tivemos respostas como

"[...] Sim, em outra equipe".

E ainda duas das atletas responderam:

"[...] quando jogo por outras equipes, além do Limoeiro, eles arcam com as despesas de viagem e me pagam um incentivo" (A2; A7).

Esse fator pode estar relacionado diretamente com as frustaçóes encaradas por essas atletas, afinal quem inicia em uma atividade, seja ela qual for, tem o sonho de se tornar profissional, e no futsal feminino não é diferente. Perguntadas sobre o sonho de se tornar profissional ou viver somente do esporte, em questão de remuneração, apenas duas das atletas não tinha esse desejo e as demais relataram:

“[...] Já pensei, mas faz tempo. É o sonho de todo mundo que gosta" (A1).

"[...] é muito complicado, porque o atleta tem tempo curto de carreira, entáo como fica o pós-carreira de atleta, fora que as remunerações são baixíssimas, tendo assim que fazer jornada dupla jogar e estudar, para quando náo tivermos o trabalho de atleta entrar no mercado de trabalho, outra barreira porque começaremos do zero, sem experiência e com uma idade um pouco mais avançada. (A2)".

"[...] estou tentando atualmente, mas é difícil" (A7).

"[...] até já tentei, mas devido a necessidade de trabalhar, acabei desistindo" (A5).

"[...] o meio do esporte feminino é muito difícil” (A8).

E aí quando vemos esse tipo de afirmação e de frustação diante das palavras, podemos concordar com o que fala Goellner ${ }^{19}$ (p.175) quando perguntada sobre as açóes mais importantes em prol do futebol de mulheres e no combate a essa cultura machista que perpassa o ambiente esportivo [...] náo podemos abandonar as mulheres no futebol. Elas possuem condiçóes pouco dignas de trabalho: não há aposentadoria, plano de saúde, carteira assinada, entre outros benefícios de direito. Grande parte delas joga por amor, pela dedicação, por uma medíocre ajuda de custo.[...] Eu penso o futebol delas como exercício de liberdade, de sociabilidade, de empoderamento.

Atualmente, mesmo com um avanço significativo da visualizaçáo e do crescimento do futsal feminino e do nível dos jogos, podemos afirmar que ainda é preciso evoluir, do ponto de vista da profissionalização. Pudemos ver que muitas buscaram a profissionalização no esporte, mas foram interrompidas pelo fato de ter que dividir o tempo esportivo com outra profissáo. Souza e Martins (2018) ao investigar a relação entre o perfil socioeconômico, a formação esportiva e a carreira esportiva em jogadoras de futsal de alto rendimento, do estado de Sáo Paulo, concluíram que o futsal como profissão para mulheres ainda é bastante precário, que "a manutenção dessa condição torna-se inviável por um prazo maior" e o futsal acaba se tornando uma carreira enquanto elas se preparam para outra.

\section{Dificuldades}

A partir de alguns discursos das atletas apontamos algumas dificuldades que são percebidas por elas na prática do futsal. Diante da pergunta sobre a dificuldade encontrada na prática de futsal feminino em Limoeiro do Norte, obtivemos respostas como:

"Eles não dão muito valor, [...] a maior queixa é reconhecimento, valorização, divulgaçáo" (A1).

"Falta de tempo" (A2; A8).

"Falta de apoio" (A3).

"Incentivo em todos os sentidos, dentro e fora de quadra" (A4)".

"Hoje em dia nós temos dificuldades em ter horários disponível para treinos, falta de verba para participar de competiçóes e também o fator motivacional que a comissão pouco incentiva e trabalha para que essa realidade mude" (A5).

"A falta de compromisso das atletas, [...] comprometimento com a equipe" (A6).

"A falta de apoio, um profissional dedicado ao futsal feminino, o número reduzido de atletas" (A7).

"Falta de interesse no futsal feminino" (A9).

A atleta Amandinha, em uma entrevista para o jornalista Matheus Henrique Vieira Ramos, em 2017, cita fatores dificultadores para o futsal feminino:

[...] a falta mesmo de visibilidade, de apoio, de força de vontade das pessoas que está no poder de fazer esse esporte grande. Entáo, o que carece muito o futsal feminino é das pessoas acreditarem e saber que aquilo também vale a pena investir.

Muitas das dificuldades estão relacionadas a estímulos externos, a motivação extrínseca seja ela de técnicos, colegas ou torcedores é de extrema importância na prática de esporte, podendo estimular na aprendizagem e melhorar o desempenho. E a partir desses estímulos positivos ou não, podemos perceber a evolução, a desistência. 


\title{
Considerações finais
}

Tratando da adesão dessas atletas ao futsal, utilizando o PMQ e analisados por categorias como sugere o instrumento, identificamos que a Competição, Competência técnica e Aptidão física são os principais motivadores da prática. Registramos ainda, que em sua maioria, não possuem remuneração para atuação e estão na prática por motivos como qualidade de vida e amor ao esporte.

Desde os anos 90, até os dias atuais, a seleção de Limoeiro do Norte vem com um elenco bem estruturado, atuando em várias competiçóes e conseguindo algumas conquistas como III Intermunicipal de futsal da federação, II Regionalito de Futsal Feminino, entre outros.

As dificuldades apontadas são: a falta de incentivo, falta de divulgação e falta de investimento. Algumas das entrevistadas tentaram crescer no esporte e outras ainda tentam, mas como apontamos, diante das respostas, é uma carreira difícil de se inserir e assim tendo que buscar outra profissão e conciliar com os treinamentos quando é possível.

No decorrer da pesquisa tivemos algumas limitaçóes, entre elas: a pesquisa sobre o futsal feminino na cidade, visto que não há acervo com os dados da modalidade, o período de treinamento e, por consequência, o número de atletas que responderam aos instrumentos de coleta.

Este estudo é um dos únicos que registram fatores motivacionais na região, gostaria de incentivar leitores e pesquisadores da área que possam levar a frente pesquisas que mostram a realidade da nossa região, do futsal, das mulheres no esporte. Estudos se fazem necessário para um melhor entendimento das situaçóes que cada grupo enfrenta.

\begin{abstract}
Adesion, permanence and difficulties encountered by women, from the city of Limoeiro do Norte in futsal: a case study

This study aimed to investigate the reasons that led women from the city of Limoeiro do Norte to seek futsal practice and their permanence in that practice. The sample consisted of nine women from a futsal team in the city of Limoeiro do Norte who are between 18 and 46 years old. For data collection we used a semi-structured interview and the Participation Motivation Questionnair (PMO) created by Gil, Gross and Huddleston (1983), translated and adapted to Portuguese by Guedes and Silvério Netto (2013) which brings as intrinsic and extrinsic factors to be chosen on a scale of 1 to 5 as "Nothing important" and "Very important", respectively. The data were analyzed by categorization as suggested by the author of the PMO and the interview was also categorized according to the purpose of the study. The results show that the athletes had predominant reasons for adhering to futsal in the categories Competition, Technical competence, Physical fitness that bring together items such as overcoming challenges, improving technical skills, maintaining physical shape and even some of the athletes were influenced by family members for this adhesion. As reasons for staying, the athletes listed the search for a better quality of life and love for the sport in question, even in the face of difficulties that are also pointed out, such as lack of time due to the double work shift that most of the interviewees have, in addition to the recognition, appreciation, commitment on the part of the athletes and also of the current management that little supports female futsal in the city. In conclusion, it is possible to affirm that the athletes are motivated mainly by external factors, but persist by internal factors, which lead to personal satisfaction and that the difficulties need the support of everyone to be overcome, since most of the difficulties mentioned are beyond the courts.
\end{abstract}

KeYwoRDs: Female futsal; Accession; Stay; Difficulties; Limoeiro do Norte. 
Adesão, permanência e dificuldades encontradas por mulheres, da cidade de Limoeiro do Norte no futsal: um estudo de caso

\section{Referências}

1. Apolo A. Futsal: Metodologia e didática na aprendizagem. São Paulo: Phorte; 2007.

2. Voser RC, Giutsi JG. O futsal e a escola: uma perspectiva pedagógica. Porto Alegre: ArtMed; 2002.

3. Moura EL. O futebol como área reservada masculina. In: Daolio J. Futebol, cultura e sociedade. Campinas, SP: Autores Associados; 2005, p. 131- 147.

4. Origem do futsal. Disponível em: http://www.cbfs.com.br/2015/futsal/origem/index.html. Acesso em: 20 jun 2019

5. Salles JGC, Moura HB. Futsal. In: Dacosta L. Atlas do esporte no Brasil. Rio de Janeiro: Shape; 2005

6. Goellner SV. Imagens da mulher no esporte. In: Priore MD, Melo VA, organizadores. História do esporte no Brasil: do império aos dias atuais. São Paulo: Unesp; 2009, p. 269-292.

7. Castellani Filho L. Educação física no Brasil: a história que não se conta. Campinas, SP: Papirus; 2010.

8. Daolio J. Cultura: Educação física e futebol. Campinas, SP: Unicamp; 2006.

9. Pereira CMS, Antunes AC. Trajetória do futsal feminino no Brasil: um caminho repleto de obstáculos. In: Seminário Internacional Fazendo Gênero 13 Mundo de Mulheres \& Fazendo Gênero 11: Transformaçôes, conexões e deslocamentos. Florianópolis - SC. Anais eletrônicos, Florianópolis: UFSC, 2017.

10. Bastos P, Navarro AC. O Futsal feminino escolar. Rev Bras Futsal Futebol. 2009.

11. Reeve J. Motivação e emoçáo. Rio de Janeiro: LTC; 2011.

12. Machado AA. Psicologia do esporte: Temas emergentes I. Jundiaí: Ápice; 1997.

13. Weinberg R, Gould D. Fundamentos da Psicologia do Esporte e do Exercício. 4a. ed. Porto Alegre: Artmed. 2008. 624 p.

14. Voser RC, Hernandez JAE, Ortiz LFR, Voser PEG. A motivaçáo para a prática do futsal: comparaçáo entre atletas federados do sexo masculino e feminino. Rev Bras Futsal Futebol. 2014.

15. Gaviao PCS, Falcão CP, Ilha PV. Adesão, permanência e barreiras percebidas na prática do futebol feminino. Rev Bras Futsal Futebol. 2018.

16. Novo clube de futsal feminino é fundado em Limoeiro do Norte. Disponível em: https://www.tvjaguar.com.br/noticia/255/ Novo-clube-de-Futsal-feminino-\%C3\%A9-fundado-em-Limoeiro-do-Norte.html. Acesso em: 10 jan 2019.

17. Machado CS, Picolli JC, Scalon RM. Fatores motivacionais que influem na aderência de adolescentes os programas de iniciação desportiva das escolas da Universidade Luterana do Brasil. Rev Digital. 2005;10(89).

18. Correia TAS, Silverio Netto JE. Motivos para a prática esportiva e fatores associados de jogadoras de futsal. Rev Mackenzie Educ Fís Esporte. 2012.

19. Vilani LHP, Samulski DM. Família e esporte: uma revisão sobre a influencia dos pais na carreira esportiva de crianças e adoslescentes. In: Silame GE, Lemos KLM, organizadores. Temas atuais VII: Educação Física e Esportes. Belo Horizonte: Editora Health, 2002.

20. Goellner SV. Os caminhos do futebol praticado por mulheres no Brasil: entrevista com Silvana Goellner. [Entrevista concedida a] Gabriel Canuto Nogueira da Gama. FuLiA / UFMG. Minas Gerais. 2018;3(3).

ENDEREÇO

Valderlene Costa do Nascimento Instituto Federal de Educação e Tecnologia do Ceará Campus Limoeiro do Norte Rua Estevão Remígio de Freitas, 1145 Monsenhor Otávio

62930-000 - Limoeiro do Norte - CE - Brasil

E-mail claudioderlene@gmail.com marcelo.alencar@ifce.edu.br
Recebido: 25/ 11/2020

Aceito: 18/ 12/ 2020 